\title{
Metastatic Mantle Cell Lymphoma to the Pituitary Gland: Case Report and Literature Review
}

\author{
Arthur Wang $^{\mathrm{a}}$ Nathan Carberry $^{\mathrm{a}} \quad$ Elena Solli $^{\mathrm{a}}$ George Kleinman $^{\mathrm{b}}$ \\ Adesh Tandon ${ }^{\mathrm{a}}$ \\ Departments of ${ }^{a}$ Neurosurgery and ${ }^{b}$ Pathology, New York Medical College, \\ Valhalla, N.Y., USA
}

\section{Key Words}

Mantle cell lymphoma $\cdot$ Metastasis $\cdot$ Pituitary gland $\cdot$ Sella turcica

\begin{abstract}
We present an unusual case of a metastatic mantle cell lymphoma (MCL) to the pituitary gland. The patient had a known history of $\mathrm{MCL}$ for which she previously received chemotherapy. She presented with new-onset diplopia and confusion, and reported a history of progressive vision blurriness associated with headache, nausea, and vomiting. MRI of the brain showed an enhancing lesion within the sella turcica involving the cavernous sinuses bilaterally, extending into Meckel's cave on the left, and abutting the optic nerves bilaterally. Following surgical excision, histopathology revealed the tumor to be a MCL. Metastatic pituitary tumors are rare and have been estimated to make up 1\% of tumors discovered in the sellar region. The two most common secondary metastatic lesions to the sella are breast and lung carcinoma followed by prostate, renal cell, and gastrointestinal carcinoma. Metastatic lymphoma to the pituitary gland is especially rare and is estimated to constitute $0.5 \%$ of all metastatic tumors to the sella turcica. To our knowledge, this is the first reported case of $\mathrm{MCL}$ metastasizing to the pituitary gland.

(C) 2016 The Author(s)

Published by S. Karger AG, Basel
\end{abstract}

\section{Introduction}

Mantle cell lymphoma (MCL) is a type of B-cell lymphoma, representing approximately $3-10 \%$ of all lymphoma diagnoses [1]. Classically, it is characterized by nuclear cyclin D1

\section{KARGER}

Arthur Wang

Department of Neurosurgery

100 Woods Road

Valhalla, NY 10595 (USA)

E-Mail wanga@wcmc.com 
Wang et al.: Metastatic Mantle Cell Lymphoma to the Pituitary Gland: Case Report and Literature Review

expression and the $\mathrm{t}(11 ; 14)$ translocation. In addition, it demonstrates CD5, CD19, and CD20 positivity along with CD10 and CD23 negativity [1].

The incidence of central nervous system (CNS) involvement in cases of MCL ranges from 4 to $26 \%$ [2]. It has been known to metastasize to the leptomeninges and brain parenchyma [3], with leptomeningeal or cerebrospinal fluid (CSF) involvement being most common [2]. Clinical manifestations have been known to include pain, numbness, cranial nerve palsy, hearing loss, headache, gait instability, paresthesia, confusion, ocular disturbances, and mental status changes [4-6].

Although cases of CNS involvement have been reported, to date there have been no reported cases of MCL metastasizing to the sella turcica, parasellar region, or pituitary gland. A total of $1 \%$ of tumors in the region of the pituitary are metastases, most commonly presenting with diabetes insipidus and anterior pituitary dysfunction [4, 7]. The two most common cancers that metastasize to this region are breast cancer at $40 \%$ and lung cancer at $33 \%$. In addition, cases of metastases of renal cell, prostate, gastrointestinal, thyroid, pancreatic, and melanoma have also occurred [4]. Rare cases of lymphoma metastasizing to the pituitary have also been reported; however, there have been no reported cases of specifically MCL metastasizing to this region [7-9]. To our knowledge, this is the first reported case of a MCL metastasis to the pituitary gland.

\section{Case Report}

Our patient is a 70-year-old female who presented with new-onset diplopia and confusion. She reported a history of progressive vision blurriness for 2 months associated with headache, nausea, and vomiting. The patient had a known history of MCL for which she previously received chemotherapy. On physical exam, she was intact except for a left sixth cranial nerve palsy. Her laboratory values were all normal with the exception of her TSH which was low.

Magnetic resonance imaging (MRI) revealed an aggressive appearing lesion within the sella turcica involving the cavernous sinuses bilaterally (fig. 1a). On the left side, the tumor extended inferiorly into Meckel's cave. The tumor encased the left posterior communicating artery at its origin, and partially encased the right posterior communicating artery. Superiorly, the suprasellar extension of the tumor did not involve the optic chiasm, but was abutting the optic nerves (fig. 1b, c).

Given the patient's neurologic deficit, as well as the findings on the MRI, an endoscopic transphenoidal resection of the lesion was performed. Intraoperative neuronavigation was utilized to confirm the location of the carotid arteries and optic nerves. Upon opening of the sella dura mater, a firm yellow lesion was encountered. An excisional biopsy was performed with debulking of the tumor. An initial frozen section revealed lymphoma.

Histopathological examination revealed the tumor to be a MCL. Microscopy of the pituitary mass showed atypical lymphocytes in diffuse sheets infiltrating into the pituitary gland (fig. 2a). The atypical lymphocytes were small with scant cytoplasm and irregular hyperchromatic nuclei with irregular nuclear contours. These lymphocytes were found to displace nests of pituitary cells. The tumor cells stained positive for the immunohistochemical stain CD20, demonstrating that the tumor cells were a clonal proliferation of B cells (fig. $2 \mathrm{~b}$ ). Flow cytometry revealed a surface lambda clonal B-cell population expressing CD19 and CD20. Taken together with the patient's known history of MCL, these findings were consistent with a metastatic MCL to the pituitary gland. 
Wang et al.: Metastatic Mantle Cell Lymphoma to the Pituitary Gland: Case Report and Literature Review

The patient did well following surgery and did not experience any new neurological deficit. Upon receiving the pathology, the patient was started on high-dose steroid therapy and her visual acuity and fields continued to improve on follow-up serial ophthalmological exams. Follow-up MRI of the brain was obtained demonstrating decreased size of the patient's pituitary tumor at both 3 and 6 months (fig. 3).

\section{Discussion}

Metastatic pituitary tumors are rare and have been estimated to make up 1\% of tumors discovered in the sella region [4]. The two most common secondary metastatic lesions to the sella are breast and lung carcinoma followed by prostate, renal cell, and gastrointestinal carcinoma [4]. Metastasis to the pituitary gland associated with lymphoma is rare compared with solid organ cancers, and is estimated to constitute a total of $0.5 \%$ of cases in the sella turcica [10]. The sella is a rare location for secondary metastasis. Metastasis to the pituitary and sellar region occurs hematogenously via the hypophyseal portal system that supplies the anterior pituitary. The posterior lobe of the pituitary is then affected by contiguous spread from the anterior pituitary [4].

The common presenting symptoms of metastatic sellar and parasellar lesions are similar to those of primary pituitary adenomas and include headaches, visual field deficits, cranial nerve palsies, and endocrine abnormalities such as diabetes insipidus [7]. Our patient presented with headaches and blurry vision. Moreover, on detailed neurologic examination, she was found to have a left sixth cranial nerve palsy. MRI of the brain revealed an aggressive lesion in the region of the pituitary gland involving the cavernous sinuses bilaterally and abutting the optic chiasm superiorly. The patient also had a right adrenal mass on CT abdomen. Because of the patient's established history of MCL, the differential diagnosis included pituitary macroadenoma and secondary metastatic MCL to the sella turcica. With corticosteroid treatment, the patient noticed improvement in her visual symptoms.

Given her clinical response to steroids, we were suspicious that it was a secondary MCL lesion that metastasized to the pituitary. An endoscopic endonasal transsphenoidal approach to the pituitary lesion was performed, which revealed a firm yellow lesion. Histological examination demonstrated MCL with diffuse sheets of atypical lymphocytes infiltrating the pituitary gland. Immunohistochemical stains were diffusely positive for CD5 and CD20. Ki-67 showed an average nuclear proliferation index of $20 \%$. Corresponding flow cytometry revealed a surface lambda clonal B-cell population expressing CD19, CD20, and coexpressing CD5 with heterogeneous expression of CD23. The final diagnosis was MCL. Analysis of CSF at the time of surgery showed a total white cell count of 297, lactate dehydrogenase of 27 and malignant cells seen on CSF cytology.

MCL is a subtype of B-cell lymphoma that accounts for $4-6 \%$ of all lymphomas and is genetically characterized by the $\mathrm{t}(11 ; 14)(\mathrm{q} 13$; q32) translocation with overexpression of cyclin D1 $[1,11,12]$. This particular subtype follows an aggressive course and patients are generally at an advanced stage with widespread metastatic lesions to the bone marrow, blood, and gastrointestinal system upon diagnosis [5]. Median age at diagnosis is the fifth to sixth decades of life and survival of patients is estimated at 3-4 years [2]. CNS involvement is rare and is an independent poor prognostic factor. It can include leptomeningeal disease (positive CSF cytology with normal neuroimaging), combined intraparenchymal and leptomeningeal disease, and very rarely intraparenchymal disease without evidence of leptomeningeal involvement (negative CSF cytology) [2,5]. It has been estimated that CNS involvement with MCL occurs in $4-26 \%$ of patients [2]. 
Wang et al.: Metastatic Mantle Cell Lymphoma to the Pituitary Gland: Case Report and Literature Review

A literature search revealed four case reports with intraparenchymal CNS involvement associated with MCL. MCL was discovered in the spinal epidural space in two of these reports, along the optic nerves in one report, and in the occipital-parietal lobe in the last case $[2,11,13,14]$. To our knowledge, we report the first case of a secondary MCL presenting as a pituitary tumor.

CNS involvement is usually a late presenting event and often seen in association with systemic relapse. The median time from diagnosis of MCL to CNS involvement was 25 months in one case series [6]. Two other publications delineated several risk factors for developing CNS disease with MCL, including blastoid morphology, elevated serum LDH, and a high Ki-67 tumor proliferation index [3, 5].

The literature regarding the appropriate management of CNS disease in MCL is limited to a few case series $[5,6,15]$. Systemic blastoid MCL without CNS disease is treated with a variety of different chemotherapy regimens depending on a patient's specific profile. The most commonly used regimens are cyclophosphamide, doxorubicin, vincristine and prednisone (CHOP) or hyperfractionated cyclophosphamide, vincristine, doxorubicin, and dexamethasone (hyper-CVAD). Once CNS disease is diagnosed, high-dose methotrexate and/or cytarabine is initiated in combination with the patient's existing regimen [5, 15]. Additionally, intrathecal therapy consisting of methotrexate, cytarabine and steroid therapy is initiated concurrently [5, 15]. The investigators from the European Mantle Cell Lymphoma Network showed that CNS involvement is an independent poor prognostic factor. They found that upon diagnosis of CNS disease, whether leptomeningeal or intraparenchymal involvement, there was a median survival of 3.7 months [5].

MCL is a rare form of non-Hodgkin's lymphoma. The blastoid variant of MCL is associated with CNS involvement in the later stages of the disease and carries a poor prognosis. We reported the first case of a metastatic MCL lesion to the pituitary gland. Transphenoidal resection of the tumor relieved our patient's neurological symptoms and provided a diagnosis. There are several trials underway that are investigating newer chemotherapeutic regimens to modulate disease progression.

\section{Statement of Ethics}

The authors have no ethical conflicts to disclose.

\section{Disclosure Statement}

The authors declare that there are no conflicts of interest.

\section{References}

1 Sander B: Mantle cell lymphoma: recent insights into pathogenesis, clinical variability, and new diagnostic markers. Semin Diagn Pathol 2011;28:245-255.

$>2$ Gurevitz S, Goldfarb J, Cooper B, et al: Biopsy-proven mantle cell lymphoma in brain parenchyma. Proc (Bayl Univ Med Cent) 2011;24:45-47.

3 Gill S, Herbert K, Miles H, et al: Mantle cell lymphoma with CNS involvement: frequency and clinical features. Br J Haematol 2009;147:83-88.

4 Altay T, Krisht K, Couldwell W: Sellar and parasellar metastatic tumors. Int J Surg Oncol 2012;2012:647256. 
Wang et al.: Metastatic Mantle Cell Lymphoma to the Pituitary Gland: Case Report and Literature Review

5 Cheah CY, George A, Gine E, et al: Central nervous system involvement in mantle cell lymphoma: clinical features, prognostic factors, and outcomes from the European Mantle Cell Lymphoma Network. Ann Oncol 2013;24:2119-2123.

-6 Ferrer A, Bosch F, Villamor N, et al: Central nervous system involvement in mantle cell lymphoma. Ann Oncol 2008;19:135-141.

7 Ogilvie M, Payne S, Evanson J, et al: Lymphoma metastasizing to the pituitary: an unusual presentation of a treatable disease. Pituitary 2005;8:139-146.

8 Koiso T, Akutsu H, Takano S, et al: Malignant lymphoma in the parasellar region. Case Rep Med 2014;2014:747280.

-9 Shaw J, Strachan F, Sawers H, et al: Non-Hodgkin lymphoma with panyhypopituitarism, hyperprolactinaemia, and sixth nerve palsy. J R Soc Med 1997;90:274-275.

$\$ 10$ Komninos J, Vlassopoulou V, Protopapa D, et al: Tumors metastatic to the pituitary gland: case report and literature review. J Endocrinol Metabol 2004;89:574-580.

11 Barnard M, Perez-Ordonez B, Rowed D, et al: Primary spinal epidural mantle cell lymphoma: case report. Neurosurgery 2000;47:1239-1242; discussion 1242.

12 Dierickx D, Wlodarska I, Vanhentenrijk V, et al: Secondary CNS involvement in cyclin D1-negative mantle cell lymphoma. Leuk Lymphoma 2008;49:2365--2366.

13 Bedotto J, Spier C, Paquin M, et al: Mantle cell lymphoma with CNS involvement. Cancer 1986;58:21252129.

14 Schwechheimer K, Hashemian A, Ott G, et al: Primary spinal epidural manifestation of malignant lymphoma. Histopathology 1996;29:265-269.

15 Bhatt VR, Loberiza FR Jr, Smith LM, et al: Clinicopathologic features, management and outcomes of blastoid variant of mantle cell lymphoma: a Nebraska Lymphoma Study Group Experience. Leuk Lymphoma 2015, Epub ahead of print. 


\section{Case Reports in Oncology}

\begin{tabular}{l|l}
\hline Case Rep Oncol 2016;9:25-32 \\
\hline DOI: 10.1159/000443682 & $\begin{array}{l}\text { ( ) 2016 The Author(s). Published by S. Karger AG, Basel } \\
\text { www.karger.com/cro }\end{array}$ \\
\hline
\end{tabular}

Wang et al.: Metastatic Mantle Cell Lymphoma to the Pituitary Gland: Case Report and Literature Review
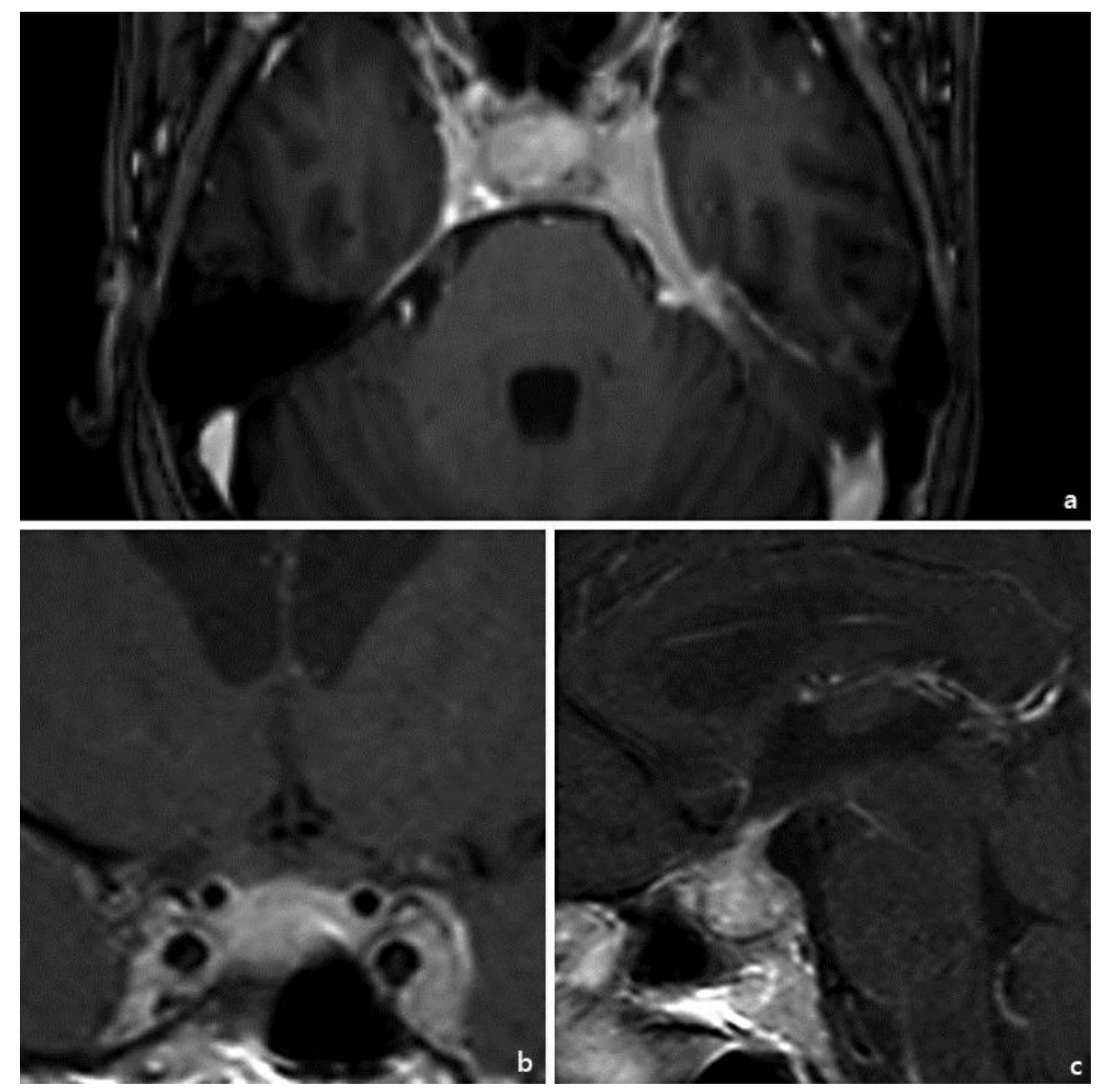

Fig. 1. Axial MRI (a) of the brain demonstrates an enhancing lesion in the sella turcica and suprasellar space with extension to the left side of the sella and along the tentorium. Coronal (b) and sagittal (c) Gdenhanced T1-weighted images demonstrate the lesion extending into the suprasellar space abutting the optic chiasm. The mass extends into the cavernous sinuses bilaterally with encasement of the bilateral cavernous carotid arteries. It also extends inferiorly on the left side into Meckel's cave. 


\section{Case Reports in Oncology}

\begin{tabular}{l|l}
\hline Case Rep Oncol 2016;9:25-32 \\
\hline DOI: 10.1159/000443682 & $\begin{array}{l}\text { (c) 2016 The Author(s). Published by S. Karger AG, Basel } \\
\text { www.karger.com/cro }\end{array}$ \\
\hline
\end{tabular}

Wang et al.: Metastatic Mantle Cell Lymphoma to the Pituitary Gland: Case Report and Literature Review

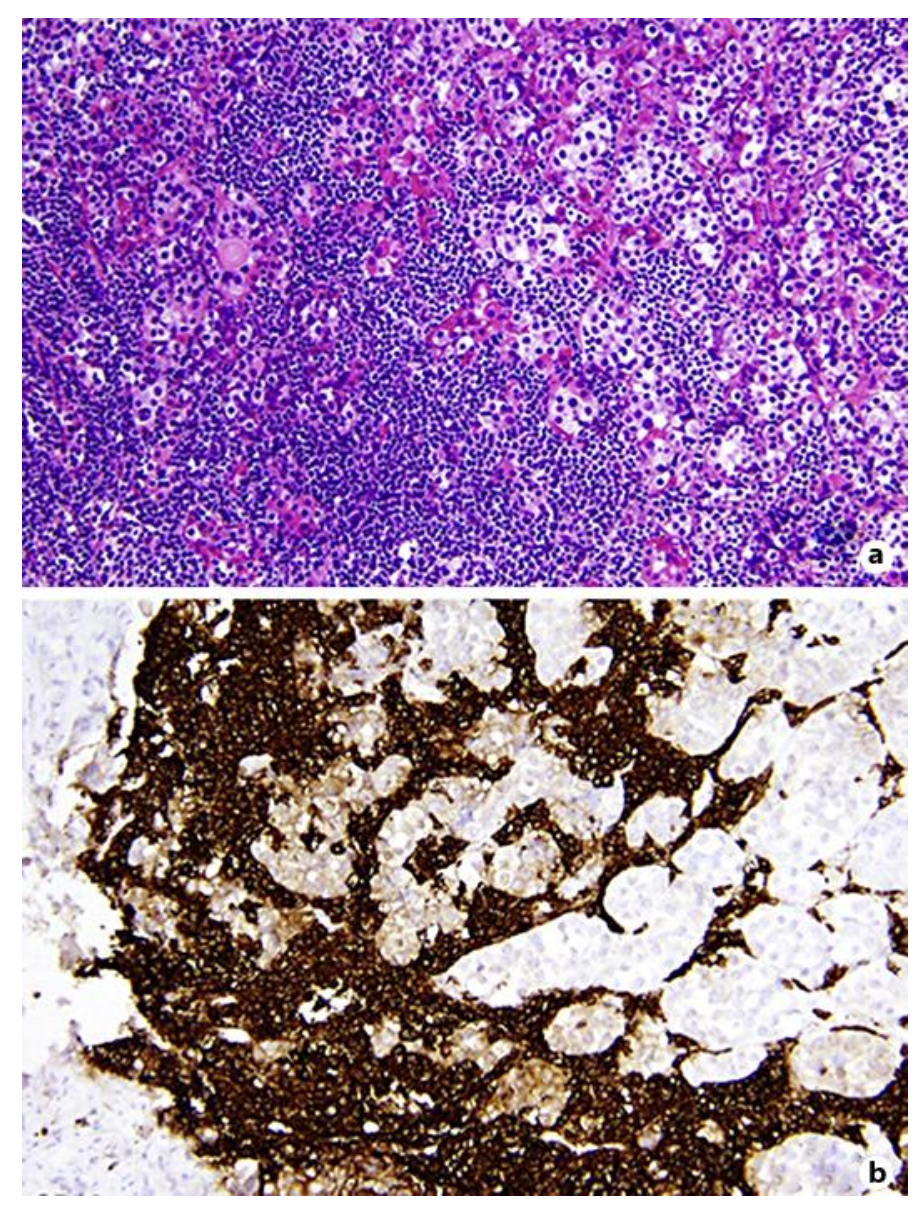

Fig. 2. Photomicrographs of tumor sections with H\&E staining (a) and immunohistochemical staining with CD20 (b). a Monotonous lymphoid cells, which have irregular hyperchromatic nuclei with irregular nuclear contours, displace nests of pituitary cells. $\mathbf{b}$ The tumor cells stained positive for immunohistochemical staining with CD20, demonstrating that they are a clonal proliferation of B cells. 


\section{Case Reports in Oncology}

\begin{tabular}{l|l}
\hline Case Rep Oncol 2016;9:25-32 \\
\hline DOI: 10.1159/000443682 & $\begin{array}{l}\text { (c) 2016 The Author(s). Published by S. Karger AG, Basel } \\
\text { www.karger.com/cro }\end{array}$ \\
\hline
\end{tabular}

Wang et al.: Metastatic Mantle Cell Lymphoma to the Pituitary Gland: Case Report and Literature Review
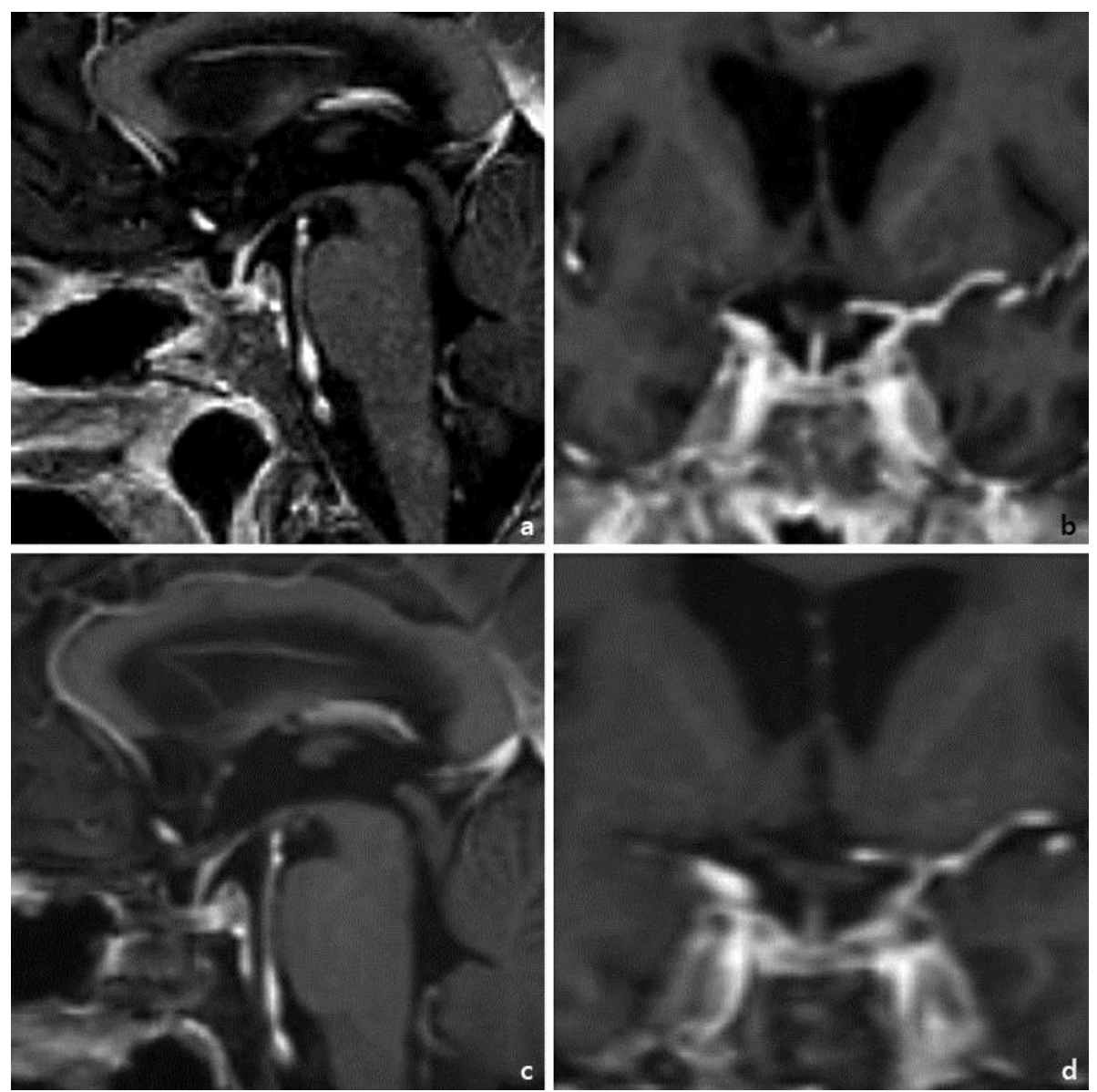

Fig. 3. Follow-up axial and coronal MR imaging at 3 months $(\mathbf{a}, \mathbf{b})$ and 6 months $(\mathbf{c}, \mathbf{d})$ post-surgery, chemotherapy, and radiation therapy demonstrate decreased size of the sellar mass, suggesting response to the treatment regimen. 